\title{
Gas-Phase Growth of Heterostructures of Carbon Nanotubes and Bimetallic Nanowires
}

\author{
Whi Dong Kim, Jung Min Park, Ji Young Ahn, and Soo Hyung Kim \\ Department of Nanosystem and Nanoprocess Engineering, College of Nanoscience and Nanotechnology, Pusan National University, \\ 30 Jangjeon-Dong, Geumjung-Gu, Busan 609-735, Republic of Korea \\ Correspondence should be addressed to Soo Hyung Kim, sookim@pusan.ac.kr
}

Received 22 November 2010; Accepted 4 January 2011

Academic Editor: Theodorian Borca-Tasciuc

Copyright ( $\odot 2011$ Whi Dong Kim et al. This is an open access article distributed under the Creative Commons Attribution License, which permits unrestricted use, distribution, and reproduction in any medium, provided the original work is properly cited.

\begin{abstract}
A simple, inexpensive, and viable method for growing multiple heterostructured carbon nanotubes (CNTs) over the entire surface of Ni-Al bimetallic nanowires (NWs) in the gas phase was developed. Polymer-templated bimetallic nitrate NWs were produced by electrospinning in the first step, and subsequent calcination resulted in the formation of bimetallic oxide NWs by thermal decomposition. In the second step, free-floating bimetallic NWs were produced by spray pyrolysis in an environment containing hydrogen gas as a reducing gas. These NWs were continuously introduced into a thermal CVD reactor in order to grow CNTs in the gas phase. Scanning electron microscopy (SEM), transmission electron microscopy (TEM), and Raman spectrometry analyses revealed that the catalytic Ni sites exposed in the non-catalytic Al matrix over the entire surface of the bimetallic NWs were seeded to radially grow highly graphitized CNTs, which resembled "foxtail" structures. The grown CNTs were found to have a relatively uniform diameter of approximately $10 \pm 2 \mathrm{~nm}$ and 10 to 15 walls with a hollow core. The average length of the gas-phase-grown CNTs can be controlled between 100 and $1000 \mathrm{~nm}$ by adjusting the residence time of the free-floating bimetallic NWs in the thermal CVD reactor.
\end{abstract}

\section{Introduction}

Low-dimensional nanostructures such as nanoparticles, nanowires, and nanotubes have strong potential for use as building blocks in the assembly of various micro- or nanoscale functional devices $[1,2]$. The fabrication of a novel heterostructure by combining different low-dimensional nanostructures can create a new opportunity in manipulating multifunctional nanostructured materials or devices. To date, numerous research groups have tried to fabricate various heterostructures, including core-shell nanowires [3], coaxial nanowires $[4,5]$, and heterojunction structures $[6,7]$ in order to realize the potentials of heterostructured materials in various application fields, including photovoltaic cells, light emitting diodes, and sensor systems.

Among the various low-dimensional functional materials, carbon nanotubes (CNTs) have drawn considerable attention from the viewpoint of design and controlled synthesis, since they offer the advantages of strong mechanical strength and high electrical/thermal conductivity. Therefore, the assembly of functional CNTs on a substrate comprising complex metallic bulk-, micro-, or nanostructures can serve as a novel method for enhancing the mechanical, electrical, and thermal properties of CNT-based composite materials or devices [8-11]. Currently, there are various synthesis methods based on wet chemistry methods; these methods have been successfully developed for synthesizing complex heterostructured CNT-metal composites that have potential for applications in energy storage [12], catalysis $[13]$, and sensors $[14,15]$. However, it is difficult to carry out the gas-phase synthesis and nanostructure control of heterostructured CNT-metal composites for achieving continuous production of composites with relatively high purity, because the size and shape of the catalytic particles continuously change because of the competition between the coagulation and coalescence processes prior to or during the chemical vapor deposition- (CVD-) assisted growth of CNTs that is accompanied by relatively high temperature processes. 

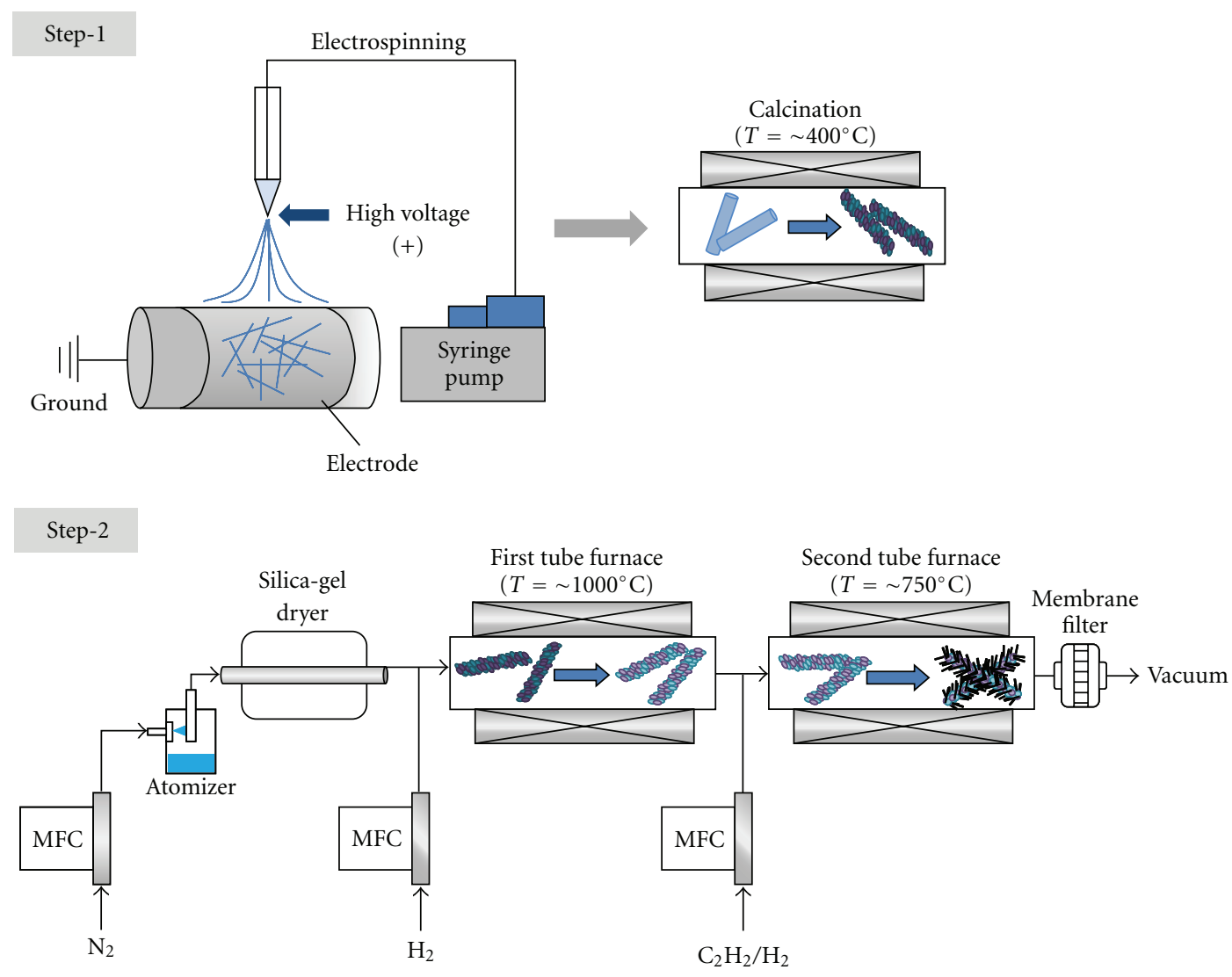

FIGURE 1: Schematic of the experimental setup.

In this study, we demonstrate a simple, inexpensive, and viable method for growing heterostructured foxtail-like CNTs with a relatively uniform diameter and controlled length on $\mathrm{Ni}-\mathrm{Al}$ bimetallic nanowires (NWs) in the gas phase. Here, the bimetallic NWs that serve as a foxtail were fabricated by a process involving electrospinning and subsequent calcination. Then, the CNTs with a relatively uniform diameter and controlled length were grown as foxtail fur in the gas phase on the entire surface of freefloating bimetallic NWs by thermal CVD.

\section{Experimental Methods}

2.1. Synthesis of Bimetallic NWs. Conventional electrospinning was carried out in order to produce bimetallic NWs as free-floating substrates for growing CNTs, as shown in the first step in Figure 1. Initially, $4 \mathrm{~g}$ of aluminum nitrate nonahydrate $\left(\mathrm{Al}\left(\mathrm{NO}_{3}\right)_{3} \cdot 9 \mathrm{H}_{2} \mathrm{O}\right.$, Sigma Aldrich) and nickel nitrate hexahydrate $\left(\mathrm{Ni}\left(\mathrm{NO}_{3}\right)_{3} \cdot 6 \mathrm{H}_{2} \mathrm{O}\right.$, Sigma Aldrich) with a molar ratio of $1: 1$ was dissolved in $4 \mathrm{~g}$ of deionized water. Further, $4 \mathrm{~g}$ of polyvinylpyrrolidone (PVP) was dissolved in $6 \mathrm{~g}$ of ethanol. Both metal nitrates and polymer solutions were then mixed in a vial by a magnetic stirrer for $30 \mathrm{~min}$. The aforementioned $\mathrm{Al}\left(\mathrm{NO}_{3}\right)_{3} / \mathrm{Ni}\left(\mathrm{NO}_{3}\right)_{3} / \mathrm{PVP}$ precursor solution was dispensed at a flow rate of $0.3 \mathrm{~mL} \cdot \mathrm{h}^{-1}$ by using a precision syringe pump (KD Scientific, Model No. 781100). When dispensing the precursor solution, a fixed positive voltage of approximately $30 \mathrm{kV}$ was applied to the tip of the syringe nozzle while simultaneously grounding the rotating plate. The distance between the nozzle tip and the rotating plate was fixed at $15 \mathrm{~cm}$ (i.e., the resulting electric field strength was approximately $\left.2.0 \mathrm{kV} \cdot \mathrm{cm}^{-1}\right)$. Subsequently, $\mathrm{Al}\left(\mathrm{NO}_{3}\right)_{3} / \mathrm{Ni}\left(\mathrm{NO}_{3}\right)_{3} / \mathrm{PVP}$ composite $\mathrm{NWs}$ were formed because of Coulombic explosion and were deposited on the surface of the iron mesh that covered the rotating plate. These composite NWs were then calcined at $400^{\circ} \mathrm{C}$ for $3 \mathrm{~h}$ in order to remove the polymer templates and simultaneously convert the metal nitrate precursor into the corresponding bimetallic oxide NWs by thermal decomposition.

2.2. Gas-Phase Growth of CNTs on Bimetallic NWs. The bimetallic oxide NWs fabricated by the previously mentioned electrospinning and calcination processes were homogeneously dispersed in deionized water by sonication at a power of $170 \mathrm{~W}$ and a frequency of $40 \mathrm{kHz}$ for $3 \mathrm{~h}$, with a total concentration of $0.1 \mathrm{wt} \%$, as shown in the second step in Figure 1. The bimetallic oxide NW solution was then aerosolized by an atomizer that was developed inhouse; the atomizer was operated at $35 \mathrm{psi}$ of compressed nitrogen gas. Microsized droplets containing bimetallic oxide NWs were rapidly transported to a silica-gel dryer by using nitrogen gas as a carrier gas at flow rates of 1.5 to $6.5 \mathrm{~L} \cdot \mathrm{min}^{-1}$. Finally, after water removal, the droplets were converted into free-floating bimetallic oxide NWs. 


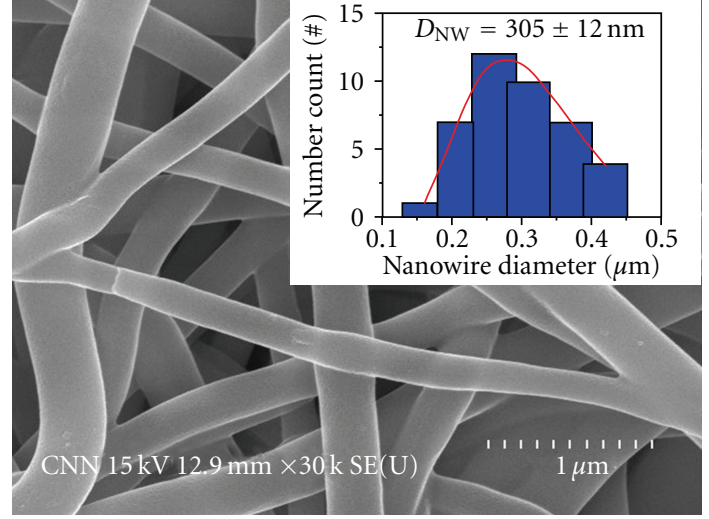

(a)

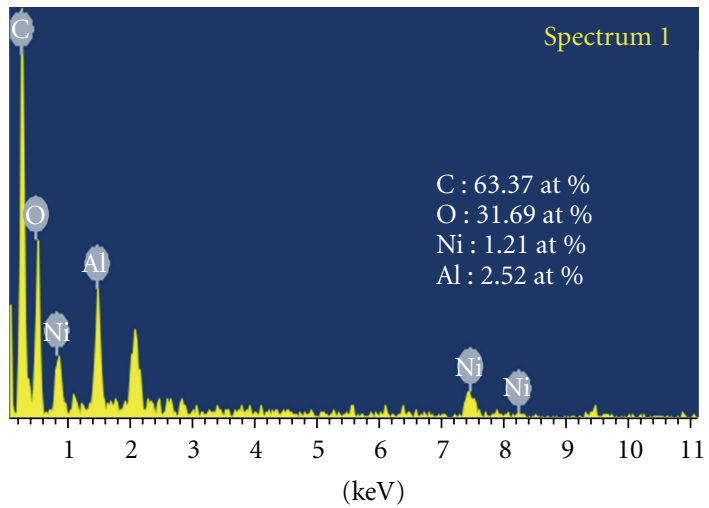

(c)

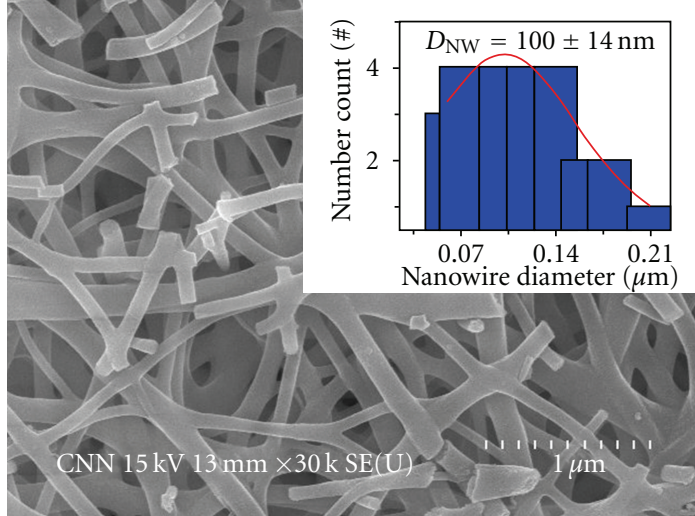

(b)

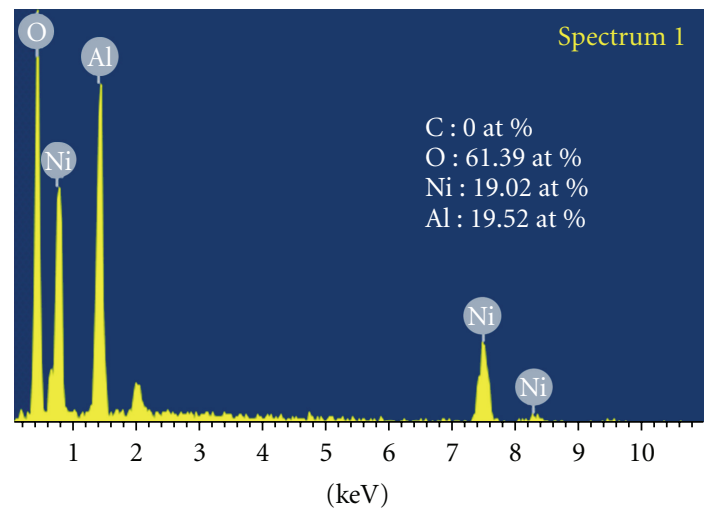

(d)

FIGURE 2: SEM images of (a) as-prepared bimetallic nitrate NWs with PVP templates and (b) postcalcined bimetallic oxide NWs (the insets show the size distribution of the NWs, $D_{\mathrm{NW}}$ is the average diameter of fabricated NWs), and the EDX results for (c) as-prepared bimetallic nitrate NWs with PVP templates and (d) postcalcined bimetallic oxide NWs.

The free-floating bimetallic oxide NWs were then continuously introduced into an environment containing hydrogen gas as a reducing gas $\left(\mathrm{H}_{2}\right.$ flow rate: $\left.100 \mathrm{sccm}\right)$ in the first tube furnace (diameter: $2.54 \mathrm{~cm}$; heating length: $30 \mathrm{~cm}$ ) that was heated to approximately $1000^{\circ} \mathrm{C}$. Thus, pure bimetallic NWs were formed. They were then continuously mixed with a controlled amount of acetylene $\left(\mathrm{C}_{2} \mathrm{H}_{2}\right.$ flow rate: $\left.\sim 10 \mathrm{sccm}\right)$ and hydrogen $\left(\mathrm{H}_{2}\right.$ flow rate: $\left.\sim 100 \mathrm{sccm}\right)$ in the second tube furnace (diameter: $5.08 \mathrm{~cm}$; heating length: $30 \mathrm{~cm}$; hereafter, the furnace is referred to as a thermal CVD reactor) heated to approximately $700^{\circ} \mathrm{C}$ in order to grow CNTs in the gas phase. The residence time of the free-floating bimetallic NWs in the thermal CVD reactor was changed from 5 to $25 \mathrm{~s}$ by controlling the flow rate of the nitrogen carrier gas between 6.5 and $1.5 \mathrm{~L} \cdot \mathrm{min}^{-1}$. The resulting aerosol CNTs grown on the free-floating bimetallic NWs were then collected on a membrane filter with a pore size of approximately $200 \mathrm{~nm}$.

\section{Results and Discussion}

The morphology of electrospun bimetallic NWs before and after calcination at $400^{\circ} \mathrm{C}$ was observed by SEM analysis, as shown in Figures 2(a) and 2(b). The mean diameter $\left(D_{\mathrm{NW}}\right)$ of electrospun bimetallic nitrate NWs with PVP templates was significantly decreased by calcination; in particular, $D_{\mathrm{NW}}$ decreased from $305 \pm 12 \mathrm{~nm}$ to $100 \pm 14 \mathrm{~nm}$. This serves as indirect evidence for the fact that the PVP templates in each bimetallic nitrate NW were thermally removed. This inference was also corroborated by the results of EDX analysis for pre- and post-calcined bimetallic nitrate NWs with PVP templates, as shown in Figures 2(c) and 2(d), which indicate that the strong carbon signature originating from the PVP templates in the bimetallic nitrate NWs disappeared after calcination.

It was important to determine whether the catalytic $\mathrm{Ni}$ sites were homogeneously distributed in the $\mathrm{Al}$ matrix in the bimetallic oxide NWs after the electrospinning and postcalcination. This is because the homogeneity of the $\mathrm{Ni}$ distribution in the $\mathrm{Al}$ matrix in the bimetallic oxide NWs is one of the important prerequisites for critically promoting the subsequent homogeneous formation of CNTs over the entire surface of the seeded bimetallic NWs. Therefore, we analyzed the bimetallic oxide NWs by scanning TEM in order to obtain the elemental mappings of $\mathrm{Ni}$ and $\mathrm{Al}$, as shown in Figure 3. The results of TEM analysis clearly 


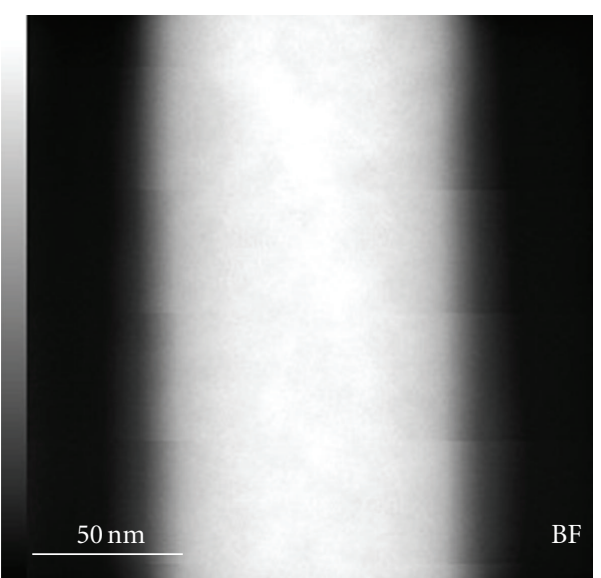

(a)

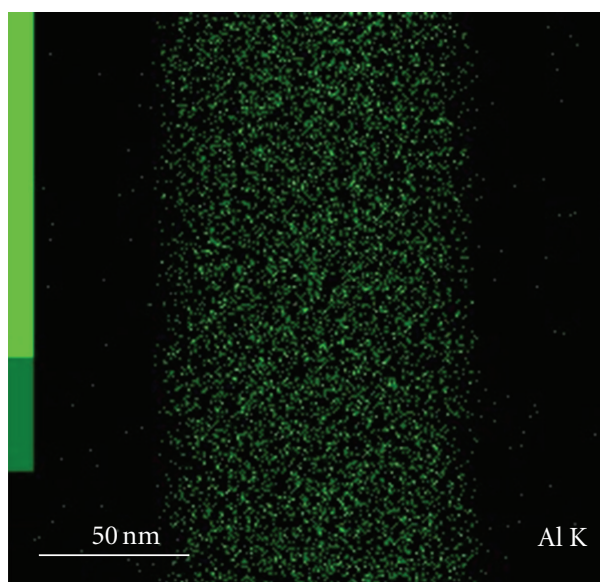

(c)

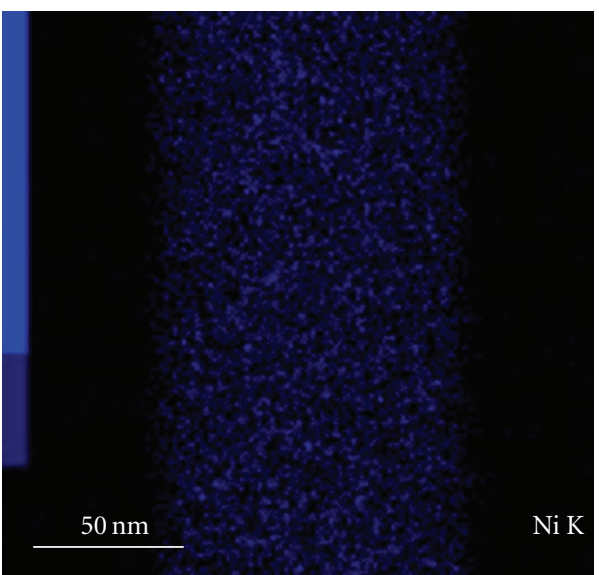

(b)

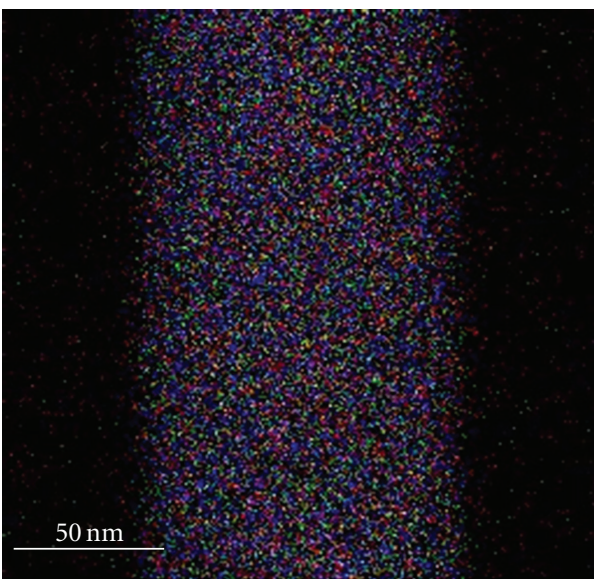

(d)

FIgURE 3: (a) STEM image of a Ni-Al bimetallic NW; each elemental mapping represents (b) Ni, (c) Al, and (d) the overlay of the Ni-Al components in a fabricated $\mathrm{Ni}-\mathrm{Al}$ bimetallic NW.

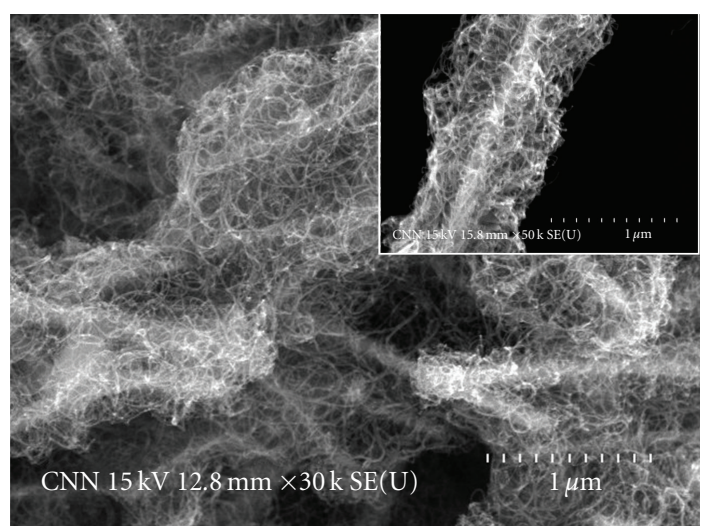

(a)

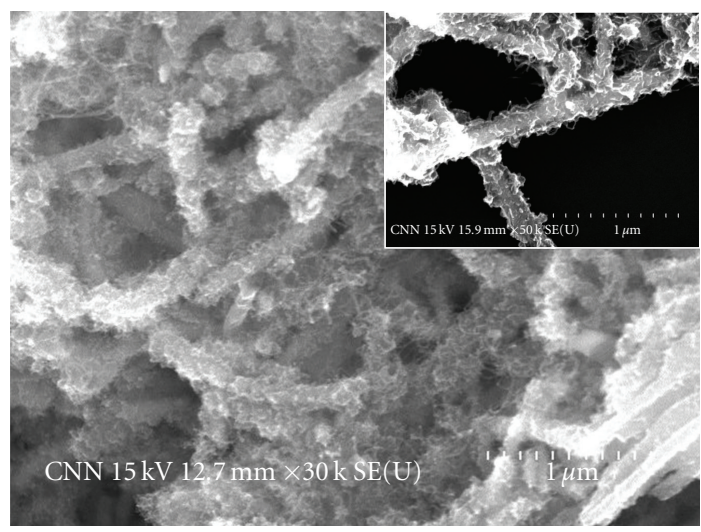

(b)

FIGURE 4: SEM images of the foxtail-like CNTs grown on Ni-Al bimetallic NWs at a residence time of (a) approximately $25 \mathrm{~s}$ (average length of CNT: $\sim 475 \pm 23 \mathrm{~nm}$ ) and (b) approximately $5 \mathrm{~s}$ (average length of CNT: $\sim 69 \pm 13 \mathrm{~nm}$ ) in the thermal CVD reactor (the insets show high-resolution SEM images). 


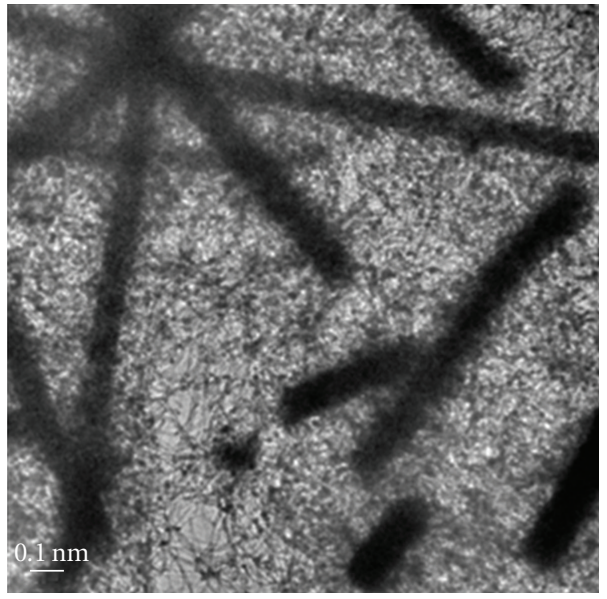

(a)

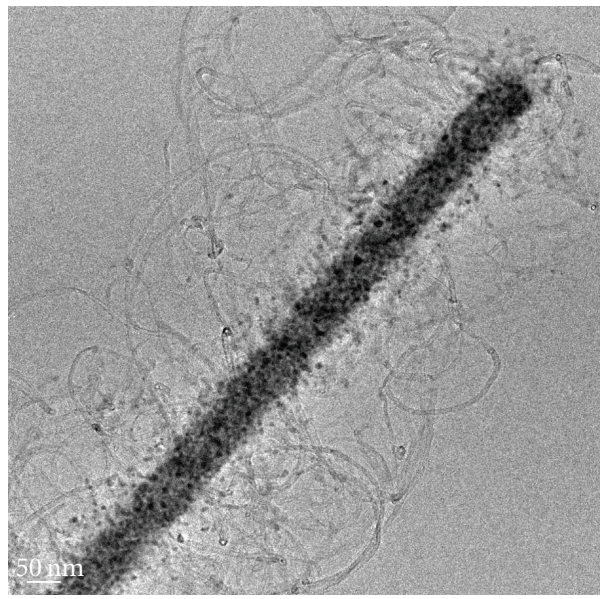

(c)

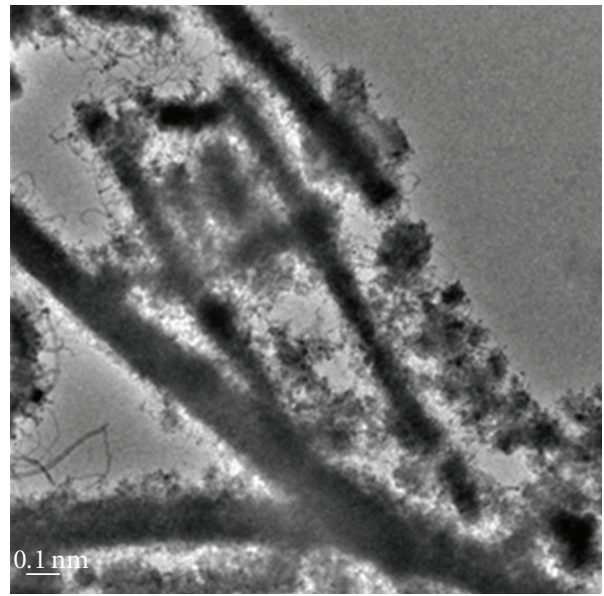

(b)

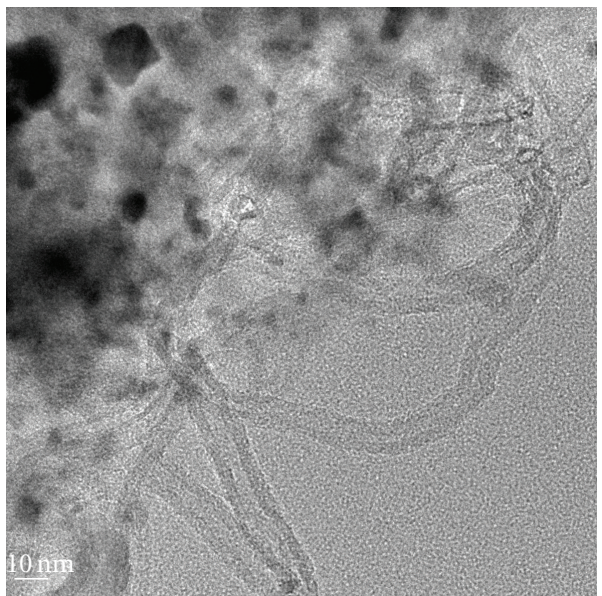

(d)

FIGURE 5: TEM images of the foxtail-like CNTs grown at a residence time of (a) approximately $25 \mathrm{~s}$ and (b) approximately $5 \mathrm{~s}$ in the thermal CVD reactor; (c) HRTEM images of the foxtail-like CNTs and (d) the interface between the bimetallic NW and the CNTs.

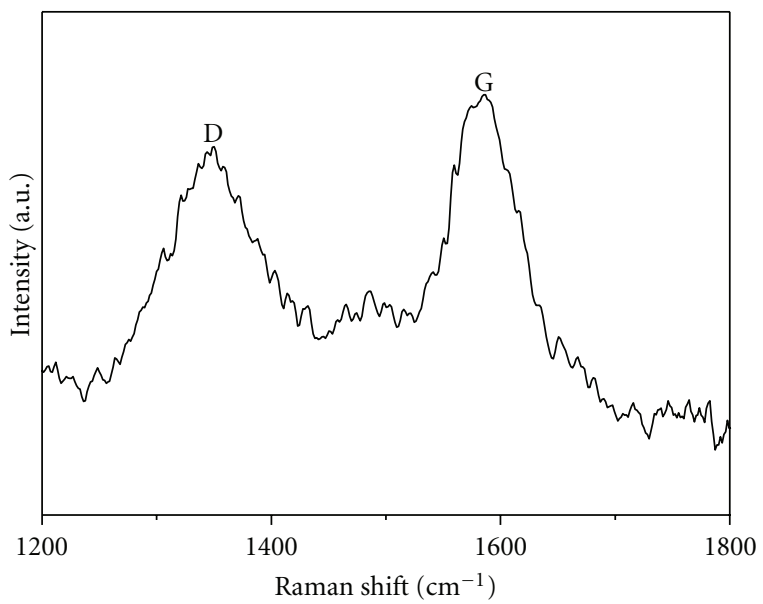

FIGURE 6: Raman spectrum of heterostructured foxtail-like CNTs grown in the gas phase. 


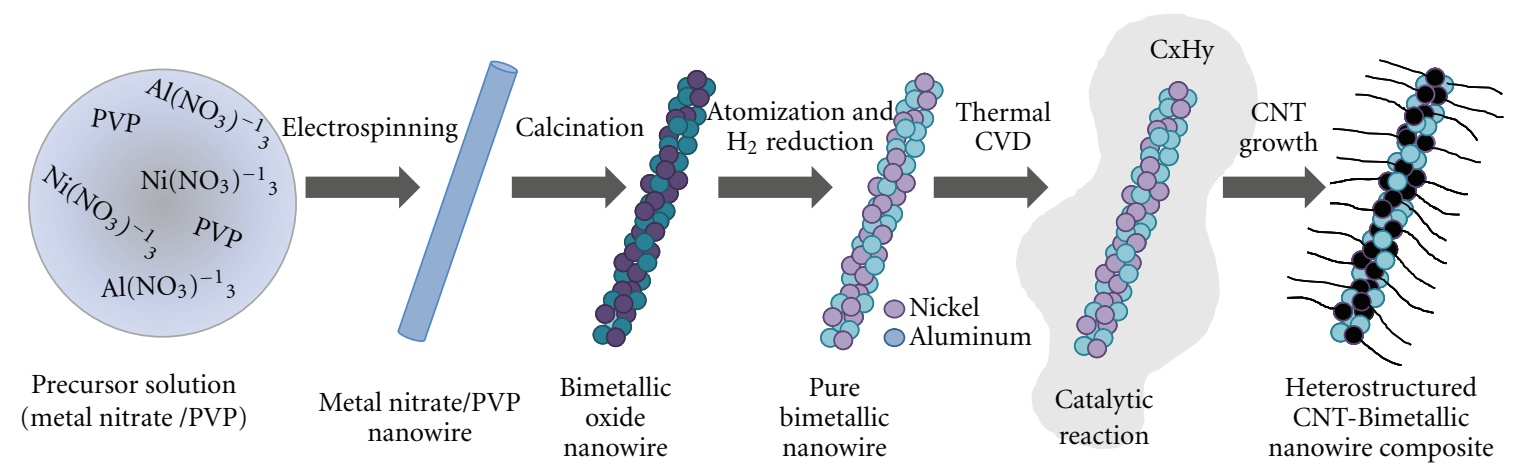

FIGURE 7: Schematic of the growth mechanism of the heterostructured foxtail-like CNTs on free-floating bimetallic NWs.

indicate that each $\mathrm{Ni}$ and $\mathrm{Al}$ signature was homogeneously distributed inside a bimetallic oxide NW fabricated by electrospinning and calcination.

The postcalcined bimetallic oxide NWs were then dispersed in an aqueous solution and aerosolized into the thermal CVD reactor containing acetylene and hydrogen in order to grow CNTs in the gas phase. Figure 4 shows that multiple CNTs were radially grown over the entire surface of bimetallic NWs and that they resembled "foxtail" structures. Here, the bimetallic NW as a foxtail bone played the role of a free-floating substrate on which multiple CNTs as a foxtail fur grew in the gas phase. In the thermal CVD reactor, acetylene decomposition and subsequent carbon precipitation occurred on the catalytic $\mathrm{Ni}$ sites that were homogeneously dispersed in the $\mathrm{Al}$ matrix inside the seeded bimetallic NWs. For a residence time of approximately $25 \mathrm{~s}$, the free-floating bimetallic NWs with an average diameter of approximately $100 \pm 14 \mathrm{~nm}$ were observed to contain CNTs with an average length of $475 \pm 23 \mathrm{~nm}$, as shown in Figure 4(a). The extent to which the CNT length could be controlled in the gas phase was tested by varying the residence time of the free-floating bimetallic NWs in the thermal CVD reactor. For this purpose, we significantly shortened the residence time of bimetallic NWs in the thermal CVD reactor by increasing the flow rate of the nitrogen carrier gas. We found that the average length of the produced CNTs was $69 \pm 13 \mathrm{~nm}$ at a residence time of approximately $5 \mathrm{~s}$, as shown in Figure 4(b). The experimental growth rate of the aerosol CNTs obtained by this approach was determined to be $15-19 \mathrm{~nm} \cdot \mathrm{s}^{-1}$. From the carbon diffusivity of $1.94 \times 10^{-9} \mathrm{~cm}^{2} \cdot \mathrm{s}^{-1}$ and carbon solubility in Ni particles (diameter: $\sim 10 \mathrm{~nm}$ ) of approximately $7.05 \times$ $10^{-3} \mathrm{~g} \cdot \mathrm{cm}^{-3}$ [14], the theoretical growth rate of CNTs was calculated to be approximately $70 \mathrm{~nm} \cdot \mathrm{s}^{-1}$. The discrepancy between the experimentally and theoretically determined growth rates for CNTs was attributed to the contamination of $\mathrm{Ni}$ sites because of the presence of the $\mathrm{Al}$ matrix and very few residual polymer templates, which appeared to significantly decrease the carbon solubility in the Ni sites. It should also be noted that at a residence time of less than $5 \mathrm{~s}$, amorphous carbon or CNT nuclei grew irregularly; this suggests that the catalytic reaction between bimetallic NWs and hydrocarbon gas did not occur to a sufficient extent within such a short residence time. Further, at residence times greater than $50 \mathrm{~s}$, there were no significant changes in the maximum average length of CNTs; this indicates that catalytic Ni sites exposed on the surface of bimetallic NWs were deactivated by coking. Therefore, we strongly believe that a critical residence time of the bimetallic NWs in the thermal CVD reactor must be achieved in order to ensure the homogeneous growth of a large population of CNTs.

As the results of TEM analysis, as shown in Figures $5(\mathrm{a})$ and 5(b), it is observed that the CNTs grown with a controlled length are immobilized since they are adhered to the surface of bimetallic NWs. Figures 5(c) and 5(d) also show that bimetallic NWs were composed of multitudinous $\mathrm{Ni}$ and $\mathrm{Al}$ grains, and the CNTs grown on the surface of bimetallic NWs have relatively an uniform diameter of approximately $10 \pm 2 \mathrm{~nm}$ and 10 to 15 walls with a hollow core. The Raman spectrum for the fabricated foxtail-like CNTs (Figure 6) corroborates the formation of multiwalled CNTs, since it shows two strong peaks at approximately $1350 \mathrm{~cm}^{-1}$ (D mode, disorder-induced band originating from defects or carbon impurities) and $1600 \mathrm{~cm}^{-1}$ ( $\mathrm{G}$ mode, stretching mode in the graphite plane), and there are no significant peaks at low frequencies in the radial breathing mode. Furthermore, the $\mathrm{D} / \mathrm{G}$ ratio at approximately 1600 and $1350 \mathrm{~cm}^{-1}$ (i.e., $I_{1600} / I_{1350}$ ), as determined from the full width at half-maximum (FWHM), was found to be approximately 1.33 . This indicates that the degree of graphitization of the foxtail-like CNTs was relatively high.

On the basis of the experimental evidence that we obtained, we suggest a possible mechanism for the growth of heterostructured foxtail-like CNTs on bimetallic NWs (Figure 7). First, Coulombic explosion of viscous bimetallic nitrates and PVP solution in the electrospinning process resulted in the production of bimetallic nitrate NWs with PVP templates. Subsequently, by calcination at $400^{\circ} \mathrm{C}$, the PVP templates were removed and the bimetallic nitrate was converted to bimetallic oxide via thermal decomposition while maintaining the form of the NWs. The bimetallic oxide NWs fabricated as mentioned above were then dispersed in an aqueous solution, aerosolized in the presence of hydrogen gas as a reducing agent, and heated to approximately $1000^{\circ} \mathrm{C}$; thus, they were transformed into free-floating pure bimetallic NWs containing both catalytic Ni sites and a noncatalytic 
Al matrix. They were continuously introduced into the thermal CVD reactor containing acetylene and hydrogen gases and were heated to approximately $700^{\circ} \mathrm{C}$. The catalytic reactions that occur at a temperature of approximately $700^{\circ} \mathrm{C}$ promote the growth of CNTs on the exposed Ni sites on the surface of bimetallic NWs.

\section{Conclusions}

We demonstrated a viable method for fabricating CNTs with foxtail-like heterostructures and a controlled length. In our method, Ni-Al bimetallic NWs as a foxtail bone were coated with radially grown CNTs as a foxtail fur. First, we carried out electrospinning and calcination in order to produce Ni-Al bimetallic NWs in which catalytic Ni sites were homogeneously distributed in a non-catalytic Al matrix. Then, by carrying out spray pyrolysis and thermal CVD, we were able to grow multiwalled CNTs with a uniform diameter of approximately $10 \pm 2 \mathrm{~nm}$ and a controlled length in the gas phase by simply adjusting the residence time of the free-floating bimetallic NWs in the thermal CVD reactor. The potential advantages of this gas-phase approach are that unagglomerated CNTs with controlled nanostructures are continuously produced with high purity at a relatively short residence time of less than approximately $50 \mathrm{~s}$. The heterostructured foxtail-like CNTs on bimetallic NWs can be used directly as reinforcements in polymer composites or as charge/heat transfer medium in multifunctional electronic materials or devices.

\section{Acknowledgments}

This study was supported for two years by a Pusan National University research grant. Whi Dong Kim and Jung Min Park contributed equally to this work as co-first authors.

\section{References}

[1] N. I. Kovtyukhova and T. E. Mallouk, "Nanowires as building blocks for self-assembling logic and memory circuits," Chemistry, vol. 8, no. 19, pp. 4354-4363, 2002.

[2] C. R. Barry, N. Z. Lwin, W. Zheng, and H. O. Jacobs, "Printing nanoparticle building blocks from the gas phase using nanoxerography," Applied Physics Letters, vol. 83, no. 26, pp. 5527-5529, 2003.

[3] L. J. Lauhon, M. S. Gudlksen, D. Wang, and C. M. Lieber, "Epitaxial core-shell and core-multishell nanowire heterostructures," Nature, vol. 420, no. 6911, pp. 57-61, 2002.

[4] D. W. Kim, I. S. Hwang, S. J. Kwon et al., "Highly conductive coaxial $\mathrm{SnO}_{2}-\mathrm{In}_{2} \mathrm{O}_{3}$ heterostructured nanowires for Li Ion battery electrodes," Nano Letters, vol. 7, no. 10, pp. 3041-3045, 2007.

[5] P. Yang, "The chemistry and physics of semiconductor nanowires," MRS Bulletin, vol. 30, no. 2, pp. 85-91, 2005.

[6] H. Sun, Q. F. Zhang, and J. L. Wu, "Electroluminescence from $\mathrm{ZnO}$ nanorods with an $\mathrm{n}-\mathrm{ZnO} / \mathrm{p}$-Si heterojunction structure," Nanotechnology, vol. 17, no. 9, pp. 2271-2274, 2006.

[7] M. C. Jeong, B. Y. Oh, M. H. Ham, and J. M. Myoung, "Electroluminescence from $\mathrm{ZnO}$ nanowires in $\mathrm{n}-\mathrm{ZnO}$ film/ $\mathrm{ZnO}$ nanowire array/ p-GaN film heterojunction light-emitting diodes," Applied Physics Letters, vol. 88, no. 20, Article ID 202105, 2006.

[8] Y. Liu and L. Gao, "A study of the electrical properties of carbon nanotube- $\mathrm{NiFe}_{2} \mathrm{O}_{4}$ composites: effect of the surface treatment of the carbon nanotubes," Carbon, vol. 43, no. 1, pp. 47-52, 2005.

[9] W. A. Curtin and B. W. Sheldon, "CNT-reinforced ceramics and metals," Materials Today, vol. 7, no. 11, pp. 44-49, 2004.

[10] S. Talapatra, S. Kar, S. K. Pal et al., "Direct growth of aligned carbon nanotubes on bulk metals," Nature Nanotechnology, vol. 1, no. 2, pp. 112-116, 2006.

[11] S. K. Pal, S. Talapatra, S. Kar et al., "Time and temperature dependence of multi-walled carbon nanotube growth on Inconel 600," Nanotechnology, vol. 19, no. 4, Article ID 045610, 5 pages, 2008.

[12] Z. Chen, Y. Qin, D. Weng et al., "Design and synthesis of hierarchical nanowire composites for electrochemical energy storage," Advanced Functional Materials, vol. 19, no. 21, pp. 3420-3426, 2009.

[13] W. Li, X. Wang, Z. Chen, M. Waje, and Y. Yan, "Carbon nanotube film by filtration as cathode catalyst support for proton-exchange membrane fuel cell," Langmuir, vol. 21, no. 21, pp. 9386-9389, 2005.

[14] J. Wang and M. Musameh, "Carbon nanotube/Teflon composite electrochemical sensors and biosensors," Analytical Chemistry, vol. 75, no. 9, pp. 2075-2079, 2003.

[15] J. Wang, "Carbon-nanotube based electrochemical biosensors: a review," Electroanalysis, vol. 17, no. 1, pp. 7-14, 2005. 

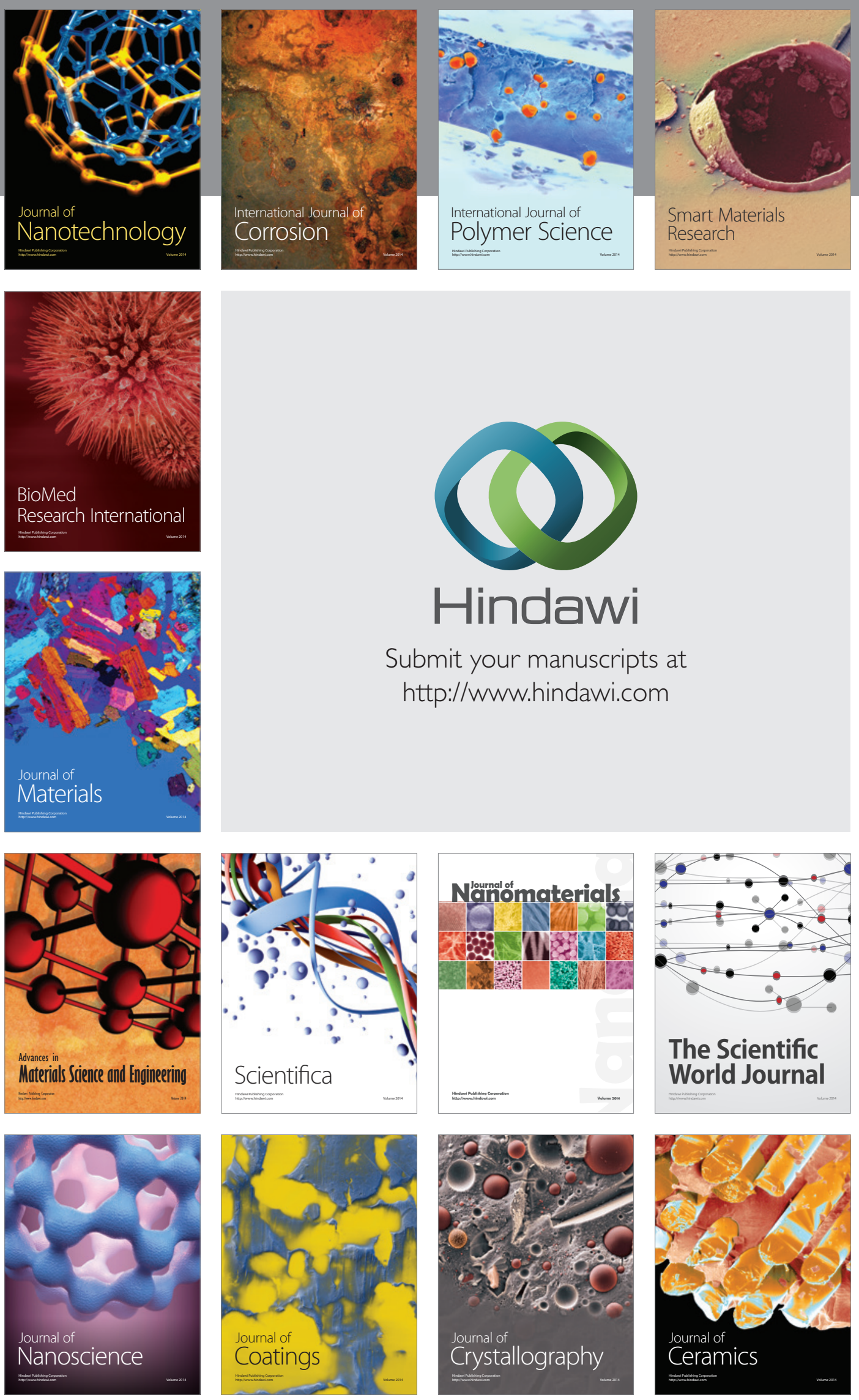

The Scientific World Journal

Submit your manuscripts at

http://www.hindawi.com

\section{World Journal}

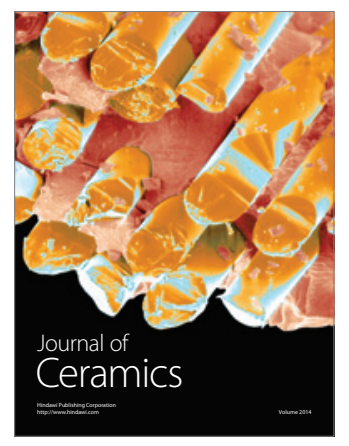

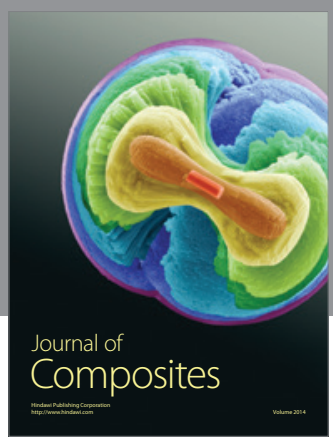
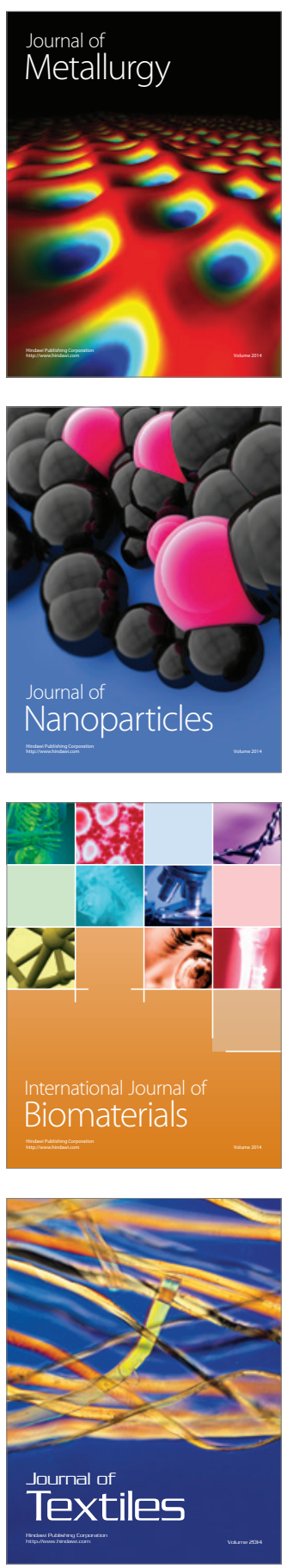